\title{
The effects of instructions, evaluative feedback, and knowledge of results upon the short-term retention of ninth graders
}

\author{
KENNETH L. WITTE and JAMES HUNTERMARK \\ University of Arkansas, Fayetteville, Arkansas 72701
}

\begin{abstract}
A factorial design was used to examine the effects of three variables upon the short-term retention of ninth grade boys. One variable was instructions; those subjects told that the task measured intelligence and was predictive of their subsequent high school academic success showed greater retention than those subjects given standard short-term memory instructions. Halfway through the task half the subjects were praised for their performance while the remaining subjects were criticized. Subsequently, retention increased for the latter, but not the former subjects. The third variable was knowledge of results; the retention of subjects told "Wrong" following each incorrect recall did not differ from that of subjects told "Right" following each correct recall. It was concluded that the effects of the first two variables upon retention were similar to those of extrinsic incentives such as shock for incorrect recall and money for correct recall.
\end{abstract}

Weiner (1966a), in a review on the effects of motivation upon memory, concluded that many of the studies in the area.were methodologically inadequate and called for the utilization of advancements in the study of short-term memory in order to conduct more careful and systematic investigations. In this regard, Weiner and his associates (Kernoff. Weiner, \& Morrison, 1966; Weiner, 1966b; Weiner \& Walker, 1966) have used the Peterson and Peterson (1959) technique to study the effects of extrinsic positive (money) and negative (shock) incentives upon short-term memory. Earlier research with this technique demonstrated that as the interval between stimulus presentation and time of recall increased, retention decreased. Weiner's research indicates that this decrease can be lessened under certain motivational conditions. Retention at the longer intervals (e.g., $15 \mathrm{sec}$ ) used by these authors was greatest when subjects were shocked for errors, intermediate when 5 cents was provided for correct recall, and lowest when no feedback was provided, whereas recall after shorter intervals (e.g., $5 \mathrm{sec}$ ) was unaffected by these incentive conditions.

Presumably, variations in intrinsic motivation should affect short-term retention in much the same manner as extrinsic motivation does. One way that intrinsic motivation may be varied is in terms of task-relevant variables such as the instructions presented to the subjects. For example, Caron and Caron (1965) found that the long-term retention of paired associates was greater for college-aged subjects told the task was related to intellectual capacity than subjects not so instructed.

The present study examined the short-term retention

Joel S. Freund sponsors this paper and takes full editorial responsibility for it. Author Huntermark is now at Livingston University, Livingston, Alabama 35470. Reprint requests should be sent to K. L. Witte, Psychology Department, University of Arkansas, Fayetteville, Arkansas 72701. of ninth-grade males after 5 and $15 \mathrm{sec}$ as related to instructions and two other task variables which presumably should affect subjects' motivation and hence, their retention. First, half the subjects were told that the task measured intelligence and hence was predictive of their subsequent high school academic success. The remaining subjects were given standard short-term memory instructions. It was predicted that the retention scores of the former subjects would exceed those of the latter subjects, but on the basis of Weiner's research, only for the 15 -sec interval. Second, midway through the task the subjects received either praise or criticism for their initial performance. It was expected that criticism would serve to heighten subjects' motivation, thereby leading to greater retention scores in the second half of the task for these subjects relative to that for praised subjects. Finally, with respect to the trial-to-trial knowledge of results provided subjects, half the subjects were told "right" following each correct answer, while the remaining subjects were told "wrong" following each error. It was expected that negative knowledge of results would also serve to heighten subjects' motivation and hence increase their retention.

\section{METHOD}

\section{Subjects}

The subjects were 40 male ninth-grade students from the Rogers, Arkansas Middle School. The subjects were preselected according to their parents' position on the Warner, Meeker, and Eels (1949) scale of socioeconomic status. Only students in the middle and upper levels of the scale were used as subjects. The testing occurred in the spring semester of the school year.

\section{Materials}

Twenty-four CCC trigrams printed on 4 x 5 -in. index cards served as stimuli. Twelve of the trigrams were from Horowitz's (1961) L12 list, with the exception that KFJ was substituted for 
JFK, while the remaining 12 triagrams were generated according to the procedure outined by Horowitz. Twenty-four different 3-digit numbers were printed on index cards and were used for an interpolated task. Two CVC trigrams printed on index cards served as training stimuli. All trigrams were presented manually.

\section{Design and Procedure}

Five subjects were randomly assigned to each of the eight groups formed by the factorial combination of the variables of instructions (evaluative vs. standard), midway feedback (praise vs. criticism), and knowledge of results (right vs. wrong).

The subjects given evaluative instructions were told that the task measured the intelligence of students about to enter high school, and that, therefore, their performance would be predictive of their academic success the next school year. The subjects given the standard instructions were simply told that the task was designed to measure human memory. All subiects were told that they would be presented a series of 3-letter syllables; they were told that a 3-digit number would follow each syllable and that they were to say the number aloud and then count backwards by three from the number as quickly as they could until stopped by the experimenter. At this point they were required to recall the 3 letters in the appropriate order. Half the subjects within each instruction group were told "right" following each correct recall, while the remaining subjects were told "wrong" following each error.

The 24 CCC trigrams were randomly divided into two groups of 12 each, with one group used for the first 12 recall trials for all subjects, and the other used for the second block of 12 recall trials. The trigrams were presented in the same order to all subjects. Prior to the presentation of the first CCC trigram, each subject was given two practice trials to acquaint them with the requirements of the task. The two CVC trigrams were used on these trials, and the retention interval was $10 \mathrm{sec}$. On these two trials and on the subsequent 24 trials, the trigram was presented for $1 \mathrm{sec}$. Within each trial block, a random 6 trials involved a 5-sec retention interval, while the remaining 6 trials involved a 15 -sec interval. A 10-sec interval occurred between recall and the start of the next trial. At the end of the first trial block, half the subjects within each instruction-knowledge of results group were told that they were doing well (praise), while the remaining subjects were told that they were doing poorly and would have to try harder (criticism). This feedback was given independently of the subject's actual performance.

\section{RESULTS}

A factorial analysis of variance was conducted on the number of correct recalls, with the factors analyzed including the between-subject variables of instructions, feedback, and knowledge of results, and the within-subject variables of retention interval and trial blocks. A .05 significance level was used for all tests.

The analysis indicated six significant statistics. The subjects given the evaluative instructions recalled more trigrams $(M=13.65)$ than subjects given standard instructions $(M=8.00),[F=49.21$, df $=1 / 32]$. Retention was greater after $5 \mathrm{sec}(\mathrm{M}=5.90)$ than after $15 \sec (M=4.92),[F=7.19, d f=1 / 32]$. Recall increased from trial block one $(\mathrm{M}=4.88)$ to trial block two $(\mathrm{M}=5.95),[\mathrm{F}=15.09, \mathrm{df}=1 / 32]$. However, follow-up analyses of a reliable Trial Blocks by Feedback interaction $[\mathrm{F}=12.42, \mathrm{df}=1 / 32]$ indicated that recall did not increase reliably for praised subjects $(\mathrm{Ms}=5.35$ and 5.45), $\mathrm{F}<1$, but did increase reliably for criticized subjects $(\mathrm{Ms}=4.40$ and 6.45$), \mathrm{F}=109.78, \mathrm{df}=1 / 39$.
Knowledge of Results was significant $[\mathrm{F}=5.28$, df $=$ $1 / 32]$. Follow-up analyses were conducted for each knowledge of results condition separately; the interaction between Instruction by Feedback was nonsignificant for the "right" condition, $\mathrm{F}<1$, and was reliable for the "wrong" condition $[\mathrm{F}=13.59$, $\mathrm{df}=$ $1 / 16]$. Further analyses indicated that, for the evaluative instruction condition, recall scores for criticized subjects $(M=15.20)$ were reliably greater than those for praised subjects $(\mathrm{M}=11.80),[\mathrm{F}=11.80, \mathrm{df}=1 / 8]$, whereas, in the standard instruction condition, recall for praised and criticized subjects ( $\mathrm{Ms}=8.80$ and 6.80 , respectively) did not differ reliably $[\mathrm{F}=1.34, \mathrm{df}=1 / 8]$.

The interaction by Retention Interval by Trial Blocks by Instructions by Feedback was significant $[F=4.65$, $\mathrm{df}=1 / 32]$. The interaction of Trial Blocks by Feedback was examined for each of the four retention interval-instructions conditions. The nature of each interaction was generally of the predicted type for each of the four conditions. However, the interaction was reliable only for the evaluative instructions 5 -sec condition $(F=10.24)$ and the standard instructions $15-\mathrm{sec}$ condition $(\mathrm{F}=6.92)$, and not for either the evaluative instructions $15-\mathrm{sec}(\mathrm{F}=1.38)$ or standard instructions $5-\sec (F=3.10)$ conditions, $\mathrm{df}=1 / 16$ in each case.

\section{DISCUSSION}

The present results indicate that the effects of intrinsic motivators upon short-term retention are generally comparable to those of extrinsic incentives. In particular, subjects given evaluative instructions, which stressed the intellectual nature of the task, recalled reliably more trigrams than subjects given standard short-term memory instructions. This finding is comparable to the results obtained by Caron and Caron (1965) for long-term retention. However, contrary to expectations, the present data indicated greater retention at both retention intervals for subjects given evaluative instructions, whereas Weiner's research with extrinsic incentives generally indicated improved retention only at the longer intervals used. This discrepancy is probably attributable to the fact that in Weiner's research, performance was near asymptote for all conditions at the shorter intervals, thus obscuring the effects of the incentives, whereas a ceiling effect was not present in this study.

Feedback was also an effective variable, as predicted. The reliable Trial Blocks by Feedback interaction resulted from increased retention for the second half of the task, relative to the first, for criticized subjects, but not for praised subjects. However, interpretation of this finding is complicated by the presence of the four-way interaction involving these two variables with retention interval and instructions. That is, the predicted double interaction was reliable for subjects given evaluative instructions only in the 5-sec condition, and for subjects given standard instructions only in the 15 -sec condition.

Knowledge of results was not an effective variable. A number of previous studies (e.g., Buss \& Buss, 1956; Curry, 1960; Spence, 1964) using a variety of conceptual and discrimination problems have consistently demonstrated that "right" for correct responding produces performance inferior to that produced by "wrong" for incorrect responding. However, research by Spence and her associates (Spence \& Dunton, 1967; Spence \& Segner, 1967) indicates that this performance 
difference is not necessarily due to a motivational difference existing between these two conditions but rather, due to an informational difference. That is, subjects in the "right" condition often incorrectly interpret no comment by the experimenter as meaning "right," while subjects in the "wrong" condition are correct in assuming that no comment by the experimenter means "right." Spence's research indicates that the performance difference between these knowledge of results conditions does not occur if subjects receive explicit instructions as to what information the absence of comment by the experimenter will provide regarding the correctness of subject's response. The present failure to find a reliable knowledge of results effect could have resulted from the fact that the preceding condition held, due to the wording of the instructions used. In addition, another possibility is that the ability of the subjects to make the correct inference regarding the meaning of no comment by the experimenter is related to their developmental level, and that these ninth graders were able to correctly deduce the meaning of no feedback in the "right" condition.

\section{REFERENCES}

Buss, A. H., \& Buss, E. H. The effect of verbal reinforcement combinations on conceptual learning. Journal of Experimental Psychology, 1956,52, 283-287.

Caron, R. F., \& Caron, A. J. Motivation as a determinant of retroactive inhibition. Journal of Verbal Learning and Verbal Behavior, 1965, 4, 17-24.

Curry, C. The effects of verbal reinforcement combinations on learning in children. Journal of Experimental Psychology, $1960,59,434$.

Horwitz, L. M. Free recall and ordering of trigrams. Journal of Experimental Psychology, 1961, 62, 51-57.

Kernoff, D., Weiner, B., \& Morrison, M. Affect and short-term memory. Psychonomic Science, 1966, 4, 75-76.

Peterson, L. R., \& Peterson, M. Short-term retention of individual verbal items. Journal of Experimental Psychology, $1959,58,193-198$

Spence, J. T. Verbal discrimination performance under different verbal reinforcement combinations. Journal of Experimental Psychology, 1964, 67, 195-197.

Spence, J. T. \& Dunton, M. C. The influence of verbal and nonverbal reinforcement combinations in the discrimination learning of middle- and lower-class preschool children. Child Development, 1967, 38, 1177-1186.

Spence, J. T. \& Segner, L. L. Verbal versus nonverbal reinforcement combinations in the discrimination learning of middle- and lower-class children. Child Development, 1967, 38, 29-38.

Warner, W. L., Meeker, M., \& Eels, K. Social class in America. Chicago: Science Research Associates, 1949.

Weiner, B. Effects of motivation on the availability and retrieval of memory traces. Psychological Bulletin, 1966a, 65, 24-37.

Weiner, B. Motivation and memory. Psychological Monographs, $1966 \mathrm{~b}, 80$, Whole No. 626 .

Weiner, B., \& Walker, E. L. Motivational factors in short-term retention. Journal of Experimental Psychology, 1966, 71, 190-193.

(Received for publication October 3, 1974.)

Bulletin of the Psychonomic Society

1975, Vol. 5 (1), 81-83

\title{
Semantic differential ratings of impoverished stimuli: A replication
}

\author{
HARVEY K. BLACK \\ State University College of New York at New Paltz \\ New Paltz, New York 12561
}

\begin{abstract}
Pictorial stimuli that progress through varying degrees of clarity were rated on semantic differential scales. As the stimuli approached clarity, they were rated more positively as well as more active and potent. Positive evaluation of clear stimuli agrees with Draguns's (1967) findings: results with respect to potency and activity are opposite in directon. The significance of the present findings with regard to motivational properties of impoverished stimuli is noted.
\end{abstract}

The examination of the properties of impoverished or ambiguous stimuli has been conducted by a number of investigators in a variety of ways. Frohlich and Laux (1969) found tachistiscopic exposure, which itself progressed from extreme ambiguity to clarity, of a series of stimuli, resulted in increases in skin conductance level. Also using psychophysiological methods, Beyn, Zhirmunskaya, and Volkov (1967) found alpha depression in the EEG records of those who viewed

This paper is sponsored by Charles N. Cofer who takes full editorial responsibility. tachistiscopically presented stimuli, which consisted of pictures of a variety of common objects.

Employing a different dependent measure, the semantic differential, Draguns (1967) also found evidence of heightened arousal, as well as negative evaluation, connected with impoverished stimuli. As these stimuli, presented in booklet form, approached clarity they were rated as being less potent, less active, and more positive. The more visually impoverished the stimuli, the more potent, more active, and less positive were the ratings. 